\title{
BENTUK PENYAJIAN TARI SAPU TANGAN DALAM ACARA MALAM BARINAI VERSI SITI ZUBAIDAH PADA MASYARAKAT PESISIR SIBOLGA
}

\author{
DWI IRNA HASANA TANJUNG \\ Prodi Pendidikan Tari
}

\begin{abstract}
The research desribed about Sapu Tangan dance (introduce dance) tahat also called as Kapri dance in Malam Barinai ceremony at Sibolga costal society. To support the analyze of the research, the writer especially used the formtheory of K.Langer. The elemens of the dance are move, accom paniment, the dressing and costum, the place of perfoemance and equipment, same as the theory of K.Langer, who also used the theory of Jazuli presentation. The proccess to produce the data of this research has done since January until March 2016. The data of research has collected by Legwork, the method that lonsist of some aspects: observation, interview theoritical aand documentation. Then the writer analyze by used kuatitative descriptive method. The result of the research as Sibolga costal soctety, is heterogeneous that consist of come ethnict. The artist of Sibolga has variant perception Sikambang that implementation at Malam Barinai.
\end{abstract}

Keywords: The form of Presentation, Malam Barinai, Sapu Tangan Dance 


\section{PENDAHULUAN}

Kesenian, salah satu unsur dari kebudayaan yang merupakan produk yang diciptakan sebagai media ungkapan untuk mencapai tujuan-tujuan tertentu dan dilaksanakan pada berbagai kegiatan baik itu upacara, hiburan, maupun pertunjukkan. Salah satu ragam kesenian yang ada di Sumatera Utara adalah Pesisir Sibolga yang disebut dengan kesenian Sikambang.

Kesenian Sikambang yang bagian pokoknya terdiri dari "tari" dan "nyanyian", pada umumya dipergunakan untuk hiburan, turun karak (turun tanah), manakkalkan anak (mengayun anak), memasuki rumah baru, penyambutan, penobatan, peresmian, pagelaran kesenian dan pernikahan. Dalam pernikahan masyarakat Pesisir Sibolga tidak hanya sekedar taridan musik iringan tetapi disertakan dengan nyanyian dan pantun-pantun bersahut-sahut yang berisi nasehatnasehat.

Tari sapu tanganmerupakantarian pembuka yangdilaksanakan kesenian Sikambang. Tariini ditarikansaatacara penyambutan,penobatan, pertunjukan dan pernikahan dalam acara malam barinai. Dilakukan oleh sepasang laki-laki dan perempuan diiringi denganlagu kapri.

Bentuk penyajian gerak tari saputangan menggambarkan tentang curahan hati dan perasaan seorang pemuda terhadap wanita yang dicintainya disaat terang bulan. Karena pada saat terang bulan para pemuda tidak turun ke laut sehingga pada saat itulah kesempatan bagi mereka untuk bertemu dalam merapatkan hubungan.

Masyarakat Pesisir Sibolga memiliki beragam seniman yang sangat berperan penting dalam eksistensi kota tersebut antara lain: Chairil Siregar, Sahriman Hutajulu, Radjoki Nainggolan, Siti Zubaidah Siregar, Edi Tanjung dan Nahar. Para seniman ini mempunyai persepsi tentang kesenian Pesisir Sibolga yang bervarian dimana kesenian Pesisir Sibolga disebut juga kesenian Sikambang terutama dalam tari sapu tangan.

Didalam tari sapu tangan terdapat beberapa varian seniman-seniman tradisi Pesisir Sibolga, dikarenakan 
seniman-seniman pesisir ini dalam pembelajarannya memiliki guru atau belajar dengan guru yang bervarian, dan pengembangan tari sapu tangan para seniman ini ingin memperlihatkan norma, etika atau keidahaan tari sapu tangan dengan persepsi mereka masing-masing

Versi Sahriman hutajulu, dan versi Siti Zubaidah tidak banyak perbedaan hanya berbeda gaya dalam penyajian tari sapu tangan mulai dari menghormat, melangkah, memegang sapu tangan dan ragam gerak yang berbeda urutannya. Namun maksud dari tari sapu tangan tersebut sama. Penulis ingin meneliti tentang tari sapu tangan versi Siti Zubaidah karena tari sapu tangan versi Siti Zubaidah yang sering dipakai atau dilaksanakan oleh masyarakat Pesisir Sibolga.

Berdasarkan latar belakang diatas, penulis merasa tertarik dan ingin mengangkat tarian tersebut menjadi topik penelitian dengan judul "Bentuk Penyajian Tari Sapu Tangan Dalam Acara Malam Bainai Versi Siti Zubaidah Pada Masyarakat Pesisir Sibolga".

\section{Landasan Teori}

Untuk membahas bentuk penyajian tari sapu tanganmaka penulis menggunakan teori bentuk K.Langer (1977:79) dan teori penyajian (1994:9).

\section{Metode Penelitian}

Pelaksanaan penelitian ini dilakukan dengan menggunakan metode kualitatif dengan pendekatan deskriptif.Hal ini dimaksudkan untuk menggali data yang masih ada, untuk memperoleh informasi dalam penelitin ini.

\section{Lokasi Penelitian}

Lokasi penelitian ini dilakukan di Kota Sibolga. Waktu yang diperlukan dalam pengumpulan data atau proses penelitian adalah dua bulan yang dilaksanakan pada bulan Januari sampai dengan Maret 2016 setelah seminar proposal dilaksanakan.

\section{Populasi dan Sampel Popilasi}

Populasi dalam penelitian ini adalah seniman yang mengetahui banyak tentang kesenian tari sapu 
tangan, penari dan pemusik yang sudah berkecimpung dalam kesenian Pesisir Kota Sibolga, tokoh-tokoh adat Pesisir Sibolga terutama Siti Zubaidah.

\section{Sampel}

Populasi yang menjadisampel dalam penelitianini adalah narasumber termasuk Siti Zubaidah, penari, dan pemusik.

\section{Teknik pengumpulan data}

Teknik pengumpulan data yang dilakukan adalah sebagai berikut:

1. Observasi

2. Wawancara

3. Dokumentasi

4. Studi pustaka

\section{Teknis Analisis Data}

Dalam penelitian ini data yang digunakan adalah analisis deskriptif kualitatif dimana penelitian ini sesuai dengan fakta sosial dan memberi gambaran, keterangan serta uraian.

\section{ISI}

\section{Gambaran Kota Sibolga}

Kota sibolga disebut juga kota berbilang kaum karena masyarakat Pesisir Sibolga merupakan masyarakat yang heterogen,terdiri dari berbagai suku yang beraneka ragam yang tinggal di Kota Sibolga.

\section{Acara Pernikahan}

Adat pernikahan didaerah Pesisir Sibolga disebut dengan adat Sumando.Sumando bagi adat Pesisir Sibolga diartikan sebagai satu kesatuan, yakni pertambahan atau percampuran satu keluarga dengan keluarga lain yang diikat dengan tali pernikahan menurut hukum Islam dan disyahkan dengan suatu acara peresmian yang disebut dengan baralek(pesta pernikahan).Tahapan kegiatan adat pernikahan Pesisir Sibolga dimulai dari Marisik, Mengantar (mangantek kepeng), Maminang (melamar), Ijab qabul dan Malam barinai, Memulangi jajak atau ngunduh (pesta di rumah pengantin pria atau marapulai). 


\section{Sejarah tari sapu tangan}

Tari sapu tangan sudah ada pada abad ke 18, tari sapu tangan tidak diketahui siapa penciptanya. Tari sapu tangan termasuk dalam kesenian Sikambang yang dilaksanakan pada adat pernikahan Pesisir Sibolga yang disebut juga dengan adat Sumando. Pada zaman dahulu tari ini hanya boleh dipertunjukkan saat malam basikambang atau malam dimana diadakannya kesenian Sikambang setelah malam barinai yang ada dalam serangkaian adat Sumando atau adat pernikahan.

Pada pertengahan abad ke 19 adat Sumando atau adat pernikahan sudah mengalami perubahan, salah satu perubahan yang terjadi yaitu ditiadakannya kepala adat atau yang disebut juga dengan Kapalo Ripe. Dengan ditiadakannya Kapalo Ripe (kepala adat) menyebabkan bersatunya acara malam barinai dengan malam basikambang, sehingga menimbulkan persepsi yang berbeda bagi masyarakat Pesisir Sibolga. Masyarakat Pesisir Sibolga hingga saat ini beranggapan bahwa malam barinai adalah malam basikambang.

$\begin{array}{ccr}\text { Pada } & \text { acara } & \text { malam } \\ \text { basikambang } & \text { atau } & \text { kesenian }\end{array}$
Sikambang dilakukan, tari sapu tangan merupakan tari pembuka dalam kesenian Sikambang, dimana tari ini menggambarkan bagimana perkenalan atau pergaulan mudamudi Pesisir Sibolga, memperkenalkan pasangannya kepada kedua orang tua masingmasing muda-mudi dan kepada masyarakat setempat hingga melangsungkan pernikahan.

Oleh karena persepsi masyarakat yang berbeda, menimbulkan anggapan yang bervariasi diantara para seniman pesisir tentang tari sapu tangan seperti Chairil Siregar, Sahriman Hutajulu, Radjoki Nainggolan, dan Siti Zubaidah yang memiliki kesamaan ragam gerak namun dengan gaya yang berbeda. Seperti menghormat, melangkah, dan memegang sapu tangan.

\section{Bentuk Penyajian Tari Sapu Tangan Dalam Acara Malam Barinai}




\section{A. Tema}

Tema dari tari sapu tangan adalah tari perkenalan, dimana sepasang pemuda-pemudi berusaha untuk mecari pasangan hidupnya dengan mengenal pasangan yang mereka pilih dengan baik, baik menurut pandangan mereka sendiri, orang tua, dan masyarakat. Agar tidak salah pilih dikemudian hari.

\section{B. Gerak}

Gerak dalam tari adalah gerak yang sudah mengalami proses penghalusan dan perombakan. Penghalusan gerak dalam tari disebut dengan stilisasi,sedangkan gerak yang sudah mengalami perombakan disebut distorsi. Gerak juga merupakan perpindahan dari suatu tempat ketempat yang lain, atau perpindahan dari suatu titik ke titik yang lain dan membutuhkan proses tenaga, ruang dan waktu.

Ragam gerak tari sapu tangan atau tari kapri berasal dari gerakan silat yang diperhalus jadi ragam gerak tari sapu tangan ini mengalami penghalusan gerak atau stilisasi, dimana ragam gerak tari sapu tangan juga mengalami perpindahan ragam gerak dari awal proses.
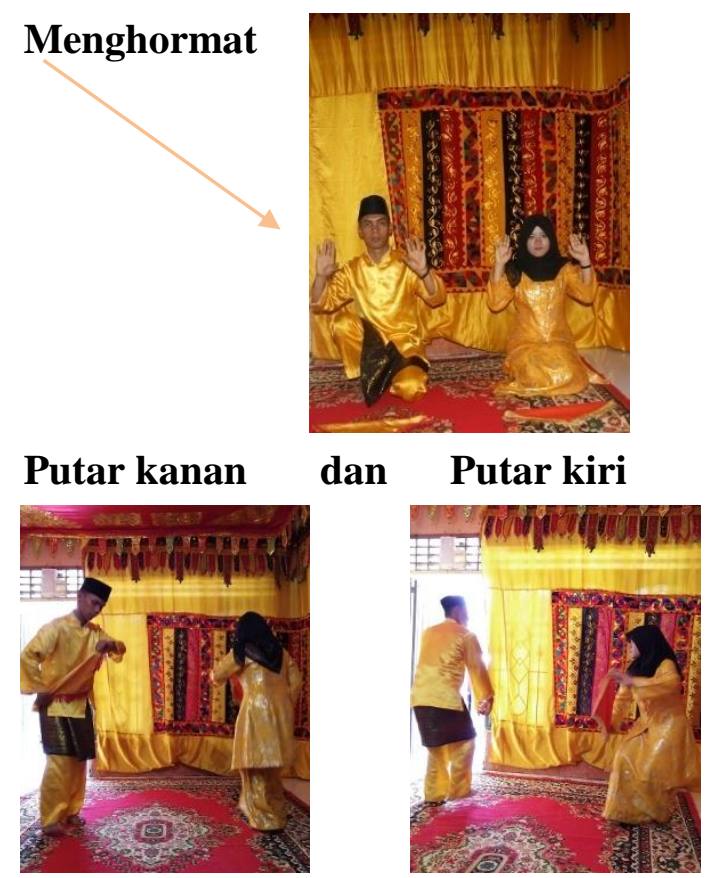

Tukar tempat

\section{Mundur merentak}
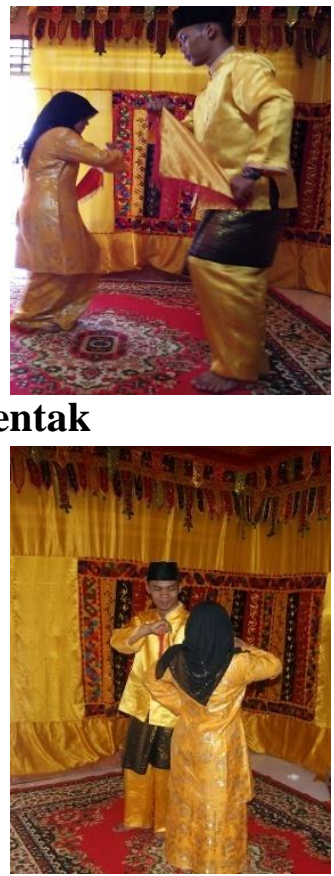

Angkat sapu tangan

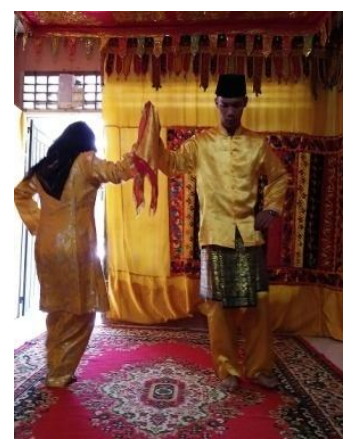


Antar sapu tangan

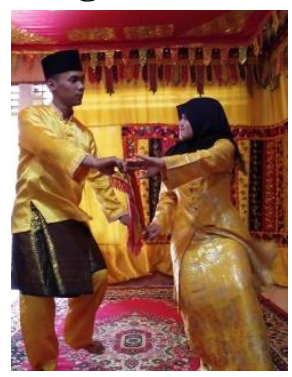

Ikat sapu tangan

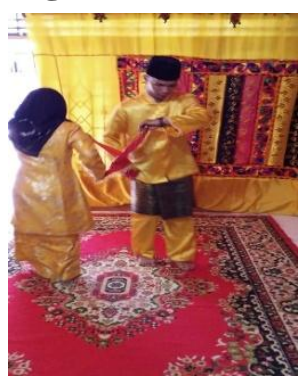

Musik tari sapu tangan

Musik iringan tari sapu tangan adalah musik kapri. Yang mana alat musik yang dipakai seperti singkadu, gandang, biola dan akordion. Adapun syair pantun yang ada dalam lagu kapriadalah :

Pulolah pandan jaulah ditanga

Pulolah pandan jaulah ditanga

Dibalik la nyo pulo duo..siangsolah

Dibalik pulo siangso la duo

Hancurla badan dikandung la tanah Hancula badan dikandung la tanah Di budi nan baik juo di kana la juo Budi nan baik dikana la juo

Kalolah indak karanolah bulan sayang

Kalolah indak karanolah bulan

Dimanolahnyola bintang o adik, manenggi la hari
Dimano bintang manenggi hari

Kalolah indak karano la tuan saying

Kalolah indak karano tuan

Indaklahnyo la kami kamari sampe la kamari

Indaklah kami sampe kamari

Limolah limo buah la dalimo tuan

Limolah limo buah la dalimo

Masaklahnyo sabua o daun

dibaliklah daun

Masaklah sabuah dibaliklah daun

Kasihlah tuan ala ditarimo dendang

Kasihlah tuan ala ditarimo

Indaklahnyo talupo o tahun saribu

latahun

Indak talupo baribu lah tahun

Pisanglah ame baoklah balai

Pasanglah ame dibaoklah balai

Masaklahnyo sabua o peti

didalamlah peti

Masaklah sabua didalamlah peti

Utanglah ame dapek la dibai

Utanglah ame dapeklah dibai

Utanglah nyo la budi o mati dibaok la mati

Utanglah budi dibaok la mati

\section{Tata busana}

Tata busana dalam tari sapu tangan dalam acara malam barinai harusa berwarna kuning, laki-laki memakai peci, baju teluk belanga, celana panjang, dan sisamping atau 
kain yang diikat kesamping. Sedangkan perempuan memakai baju kurung.

\section{Tata rias}

Tata rias atau make up yang dipakai saat acara malam barinai pada wajah perempuan cantik dan laki-laki tampan

\section{Tempat (pentas)}

Tempat atau pentas pertunjukkan tari sapu tangan dalam acara malam barinai ini rendah atau sejajar dengan marapulai (pengantin pria) dan anak daro(pegantin wanita).

\section{Properti}

Properti yang dipakai saat menarikan tari sapu tangan dalam acara malam barinai ini adalah sapu tangan seperti nama tari tersebut yaitu tari sapu tangan.

\section{Pola lantai}

Pola lantai pada tari sapu tangan setengah lingkaran, zigzag, horizontal, dan diagonal.

\section{PENUTUP}

\section{Kesimpulan}

Banyak cara yang dilakukan untuk mendapat informasi yang dibutuhkan. Salah satunya adalah mengumpulkan data dengan melakukan penelitian. Sehingga hasil penelitian yang terdapat pada Bab VI, yang telah dilaksanakan di daerah Pesisir Sibolga dengan pokok penelitian sebagaimana yang telah dijabarkan, maka penulis membuat kesimpulan diantaranya adalah sebagai berikut :

1. Adat istiadat pesisir termasuk kesenian Sikambang adalah jati diri dari masyarakat Sibolga. Kesenian Sikambang hanya ada dan dimiliki oleh masyarakat Pesisir Sibolga dan digunakan oleh masyarakat yang sudah merasa bagian dari kelompok budaya/etnis Pesisir Sibolga.

2. Tari sapu tangan adalah salah satu kesenian yang sering digunakan masyarakat Pesisir Sibolga dalam berbagai acara seperti pernikahan, hiburan, upacara adat hingga sekarang. Tari sapu tangan ini memiliki keberagaman gerak, seirama dengan musik pengiringnya yaitu musik kapri. Sedangkan bentuk penyajian tari sapu tangan harus berpenampilan atau berpakaian sopan. Pada acara pesta pernikahan dilakukan pada malam hari atau malam barinai (malam basikambang), yang disajikan 
secara berpasangan dan diiringi musik kapri, begitu juga untuk hiburan bentuk penyajiannya dilakukan bisa siang, bisa malam sesuai acara yang dibutuhkan.

3. Maksud dari keseluruhan bentuk penyajian tari sapu tangan pada masyarakat Pesisir Sibolga menggambarkan tentang bagaimana cara sepasang muda-mudi berkenalan hingga mingikat tali pernikahan.

\section{A. Saran}

Berdasarkan kesimpulan yang telah dijabarkan diatas, maka penulis dapat memberikan beberapa saran, diantaranya sebagai berikut :

1. Pesisir Sibolga yang terdiri dari masyarakat yang heterogen diharapkan dapat terus menjaga hubungan kekeluargaan antar suku yang ada didaerah Pesisir Sibolga.

2. Kepada pemerintah daerah Pesisir Sibolga selalu member perhatian, agar tetap mempertahan atau melestarikan tari sapu tangan supaya tidak punah sebagai wujud kepedulian terhadap tradisi Pesisir Sibolga.

3. Disarankan kepada seluruh lapisan masyarakat agar senantiasa menggunakan adat istiadat yang berlaku guna melestarikan budaya yang nantinya memberikan suatu jati diri atau identitas bagi masyarakat Pesisir Sibolga.

4. Penulis berharap kepada seniman kesenian Sikambang yang ada didaerah Pesisir Sibolga agar terus menjaga dan mengembangkan kesenian yang ada di daerah Pesisir Sibolga dan sekitarnya.

5. Perlu dilakukan pelestarian budaya dengan mengajarkan kepada generasi muda untuk mengenal budaya sendiri hingga dimasa yang akan datang agar budaya pesisir tidak hanya tinggal menjadi sebuah nama. 


\section{DAFTAR PUSTAKA}

Ady,Mitri Manalu.

2006.

"Musiksikambang

dalamPernikahan

Sumando".Skripsi

untuk

memenuhi derajat Sarjana S-1

pada Program Studi

SeniMusik, Jurusan

Sendratasik, Universitas

Negeri Medan.

Djuharie o. Setiawan.2001. Pedoman Penulisan Skripsi Tesis Disertasi.Bandung: Yrama Widya

Hutagalung, H.R Jafar. 2004. Tata Cara Pelaksanaan Perkawinan Dalam AdatIstiadat Pesisir Sibolga Dan Sekitarnya.Medan: Depdikbud Sibolga.

Lubis, Solly. 1998. Sibolga danSekeping

Sejarahnya.Dalam Hari Jadi KotaSibolga. Sibolga: Pemko Sibolga

Luckman, H.T Sinar, dkk. 2010. Mengenal Adat Budaya Pesisir Tapanuli

TengahSibolga.Medan:

Forkala Sumut.

Masliannur, Juli Elvina. 2014. "Makna Simbol Tari Payung Pada MasyarakatPesisir Sibolga di Kecamatan Sibolga Kota Tapanuli Tengah", Skripsiuntuk memenuhi derajat S-1 pada Program Studi Seni Tari, JurusanSendratasik, Universitas Negeri Medan
Nenta, Evi Sipahutar. 2012. Fungsi Dan Struktur Tari Anak Yang Diiringi MusikSikambang Dalam Upacara AdatPerkawinan Masyarakat Pesisir SibolgaTapanuli Tengah Dikecamatan Sibolga Kota.Skripsi untuk memenuhiderajat S-1 pada Jurusan Etnomusikologi, Universitas Sumatera Utara.

Nurwani. 2014. "Bahan Ajar PengetahuanSeni Tari”.UNIMED Press.

Pasaribu, Syawal (2014). "Bunga Rampai Pesisir Kota Sibolga”, Buku tentangBudaya dan Adat Pesisir Sibolga.

Ruwaidah. 2014. "Kesenian Sikambang: Prespektif Multikultural sebagaildentitas Budaya Pesisir Sibolga", Skripsi untuk memenuhi derajat $S$ 1pada Program Studi Seni Tari, Jurusan Sendratasik, Universitas NegeriMedan

Salim dan Syahrun. 2007. MetodologiPenelitian Kualitatif.Bandung: CitapustakaMedia

Sedyawati, Edi. 1986. Pengetahuan Elementer Tari dan Beberapa Masalah Tari.Jakarta: Direktorat kesenian Proyek Pengembangan Kesenian Jakarta,Departemen pendidikan dan Kebudayaan

Simatupang, Sahat. 2014. "Negeri Berbilang Kaum". Bahan Bacaan TerhadapPemahaman 
Masyarakat Pesisir Sibolga Tentang Negeri Berbilang Kaum,Sibolga Tapanuli Tengah

Simbolon, Nurdiansyah. 2008. " Tari Adok pada Upacara Adat Sumando dalamPernikahan Masyarakat Pesisir Sibolga Tapanuli Tengah”, Skripsi untukmemenuhi derajat S-1 pada Program Studi Seni Tari, Jurusan Sendratasik,Universitas Negeri Medan

$\begin{array}{lr}\text { Sinar, Tengku } & \text { Luchman } \\ \text { (2011) "Lintasan } & \text { Sejarah } \\ \text { Sibolga dan } & \text { Pantai } \\ \text { BaratSumatera } & \text { Utara", } \\ \text { Jurnal } & \end{array}$

Siregar, Siti Zubaidah. 2008. "Tari Tradisional Daerah Pesisir Pantai BaratKotamadya Sibolga”, Makalah pada Penyuluhan Tentang Tari TradisionalDi Pesisir Sibolga, Sibolga

Siregar, Siti Zubaidah (2014). "Budaya Pesisir Sibolga kelas 1 SMP”, Didalambuku pelajaran kurikum muatan lokal SMP

Sugiyono. 2008. Metode Penelitian Kuantitatif Kualitatif dan $R \& D$. Bandung:Alfabeta

Wahyuni, Nila Lubis, 2011. "Tari perak-perak Pada Masyarakat TapanuliTengah di Kecamatan Medan Johor Kota Medan," Skripsi untukmemenuhi derajat S-1 pada Program Studi Seni Tari, Jurusan
Sendratasik,Universitas

Negeri Medan 